\title{
DESCRIÇÃO DE RECURSOS IMAGÉTICOS DIGITAIS: APRESENTAÇÃO DE UM MODELO CONCEITUAL
}

\author{
Ana Carolina Simionato* \\ Universidade Estadual de Londrina - UEL, Brasil. \\ Plácida L. V. Amorim da Costa Santos** \\ Universidade Estadual Paulista - UNESP, Brasil.
}

\begin{abstract}
Resumo: As técnicas de captura de imagem têm avançado juntamente com as tecnologias de informação e comunicação e números inimagináveis de informações imagéticas estão armazenados e disponíveis nos ambientes digitais. O objetivo deste estudo é apontar as dificuldades encontradas na construção de representações de recursos imagéticos digitais com uso dos instrumentos disponíveis para o tratamento descritivo da informação. Como resultados tem-se o mapeamento de elementos descritivos para imagens digitais resultante da análise dos esquemas de orientação para a construção de registros descritivos (AACR2r, ISBD, Graphic Materials, RDA, CDWA, CCO) e do modelo conceitual FRBRer. A análise conduziu a construção do modelo conceitual, Requisitos Funcionais para Dados Imagéticos Digitais - RFDID, para a elaboração de formas mais eficientes para representar o recurso imagético de modo a torná-lo disponível, acessível e recuperável, a partir da persistência dos dados descritivos, da flexibilidade, da consistência e da integridade como requisitos essenciais para a representação da imagem digital.

Palavras-chave: Imagem digital; Requisitos Funcionais para Dados Imagéticos Digitais - RFDID; requisitos funcionais; modelagem conceitual; informação e tecnologia.
\end{abstract}

\begin{abstract}
Título: DESCRIPCIÓN DE LOS RECURSOS DE IMÁGENES DIGITALES: PRESENTACIÓN DEL MODELO CONCEPTUAL.

Resumen: Las técnicas de captura de imágenes han avanzado junto con las tecnologías de la información y comunicación. Así un número inimaginable de informaciones y de imágenes son almacenados y están disponibles en entornos digitales. El objetivo de este estudio es señalar las dificultades encontradas en la construcción de representaciones de recursos de imágenes digitales con el uso de los instrumentos disponibles para el tratamiento descriptivo de la información. Como resultados se destacan el mapeo de los elementos descriptivos para imágenes digitales resultantes del análisis de los sistemas de orientación para la construcción de registros descriptivos (AACR2r, ISBD, Materiales Gráficos, RDA, CDWA, CCO) basado en el modelo conceptual FRBRer. El análisis ha llevado a la construcción del modelo conceptual Requisitos Funcionales para Datos de Imágenes Digitales RFDID, para desarrollar formas eficientes para representar los recursos de imágenes y hacerlos accesibles y recuperables, por medio de la persistencia de los datos descriptivos, de la flexibilidad, de la consistencia y de la integridad, como requisitos esenciales para la representación de la imagen digital.
\end{abstract}

Palabras clave: Imagen digital; Requisitos Funcionales para Datos de Imágenes Digitales -RFDID; requisitos funcionales; modelado conceptual; información y tecnología.

Title: DESCRIPTION OF DIGITAL IMAGE RESOURCES: PRESENTATION OF A CONCEPTUAL MODEL. Abstract: Techniques of image capture have advanced along with the technologies of information and communication and unthinkable numbers of information available and imagery are stored in digital environments. The objective of this study is point out difficulties found in the construction of imagetic representations of digital resources using the instruments available for the treatment of descriptive information. The results we have the mapping of descriptive elements to digital images derived from analyzing of the schemes to guide the construction of descriptive records (AACR2R, ISBD, Graphic Materials, RDA, CDWA, CCO) and the conceptual model FRBRer. The result of this analysis conducted the conceptual model, Functional Requirements for Digital Imagetic Data - RFDID to the development of more efficient ways to represent the use of imagery in order to make it available, accessible and recoverable from the data persistence descriptive, flexibility, consistency and integrity as essential requirements for the representation of the digital image.

Keywords: Digital image; Functional Requirements for Digital Imagetic Data - RFDID; functional requirements; conceptual modeling, information and technology.

\footnotetext{
* anacarolina.simionato@uel.br

**acida@marilia.unesp.br
}

Recibido: 15/07/2013; $2^{\text {a }}$ versión: 19/09/2013; aceptado: 22/09/2013.

SIMIONATO, A.C. y AMORIM DA COSTA SANTOS, P.L.V. Descrição de recursos imagéticos digitais: apresentação de um modelo conceitual. Anales de Documentación, 2013, vol. 16, nº 2. Disponible en: http://dx.doi.org/10.6018/analesdoc.16.2.179261 


\section{INTRODUÇÃOO.}

A popularização da captura e da criação de imagens por meios digitais, gerou processos cada vez mais simples e acessíveis para a criação de informações imagéticas, mas com eles vieram grandes dificuldades para os métodos de representação, busca, de acesso e de recuperação dos objetos digitais imagéticos, além de alterarem seu uso e reuso.

O ambiente digital oferece a possibilidade de armazenamento e acesso instantâneos às imagens capturadas a todo o momento por diversos dispositivos, como celulares e câmeras; entretanto, transformar a imensa quantidade de dados disponíveis diariamente em informações consistentes e que garantam uma economia no processo de acesso e de recuperação da informação é um desafio. Nesse contexto, a construção de formas de representação passa a ser uma exigência para que dados, informações e recursos possam ser gerenciados para a otimização da identificação, localização, acesso, recuperação, uso, reuso e preservação de objetos imagéticos digitais.

A tentativa de padronização das formas de representação da informação sempre foi uma preocupação no desenvolvimento de instrumentos adequados para a descrição recursos de modo a garantir sua individualização e facilitar sua localização. A efetiva sistematização de regras para a padronização da construção de catálogos começou com as bibliotecas modernas, caracterizadas por um público variado, aumento da demanda informacional e variedade de recursos informacionais.

$\mathrm{O}$ recurso informacional, definido como qualquer objeto com uma sintaxe informacional, para ser localizado necessita de registro e de descrição. A imagem digital, como um recurso informacional iconográfico, requer por sua vez, orientações precisas e específicas para seu tratamento descritivo. As orientações para o tratamento descritivo informacional compreendem a análise sistemática e a descrição dos elementos de uma imagem para sua identificação, localização, acesso e recuperação, tornando possível ao usuário dos ambientes informacionais a apropriação das informações disponíveis.

Destaca-se assim, a importância da catalogação na preparação do recurso imagético digital a partir da construção de formas eficientes para descrevê-lo, representando-o de maneira a torná-lo disponível e acessível. Nesse sentido, é requerido um esforço na padronização das orientações para a descrição do material imagético digital que favoreça a clareza na compreensão das diferenças entre a imagem analógica e a digital.

Até a apresentação dos Functional Requirements for Bibliographic Records (FRBR), o processo de catalogação não tinha como uma de suas tarefas,

\section{[...] a representação conceitual dos elementos que comporão os metadados do catálogo, ficando a critério de um profissional da Computação fazer o mapeamento dos elementos definidos pelo catalogador numa estrutura conceitual de entidade, atributos e relacionamentos entre os itens bibliográficos, e consequentemente responsáveis pela construção do modelo conceitual. (Santos, 2010, p. 219).}

A essência do tratamento descritivo informacional continua a mesma, os catalogadores produzem e padronizam metadados desde as primeiras iniciativas de organização da informação. E os profissionais de outras áreas do conhecimento têm criado, especialmente com os avanços tecnológicos, novos métodos de tratamento da informação, deixando de lado, muitas vezes, o que já foi desenvolvido e algumas soluções estratégicas e metodológicas para a otimização do processo de descrição de recursos da área da Ciência da Informação e suas aplicações na Biblioteconomia e na Arquivologia.

Nesse sentido, o conceito de metadados para o domínio bibliográfico é apresentado na condução de uma abordagem sobre a modelagem conceitual para a representação da imagem digital, ou seja, o atributo deve estar ligado a um valor exato que o diferencia de todos os outros atributos, da mesma forma durante o processo de modelagem, a entidade e suas propriedades devem estar em um estado oblíquo que seja capaz de se relacionar com outras sem a necessidade de duplicação.

Assim, os dados descritivos serão persistidos, definidos como valores únicos, levando em conta seu domínio e acesso para o instanciamento. Esta proposta parte da possibilidade de que a persistência e instanciamento dos dados serão definidos a partir do mapeamento de elementos descritivos resultante da análise de instrumentos de orientação para a construção de registros descritivos e do modelo Entidade-Relacionamento. 
É importante destacar que a apresentação do modelo conceitual para recursos imagéticos não propõe a criação um novo padrão de metadados para as imagens digitais, pois já existem vários padrões disponíveis, mas sim afirmar que uma descrição mais específica e detalhada sobre o recurso imagético, pode ser a solução para diversos problemas ligados aos catálogos e banco de dados de imagens digitais.

\section{METADADOS PARA IMAGENS DIGITAIS.}

Os metadados foram desenvolvidos para racionalizar, diferenciar e tratar o fluxo informacional e consequentemente descrever recursos para melhorar a sua recuperação nos ambientes informacionais. Os metadados auxiliam na organização das fontes eletrônicas, favorecem a interatividade, validam as identificações e asseguram a preservação dos dados e das informações.

O uso do termo metadados se tornou mais intenso em diversas áreas do conhecimento a partir da proposta de realizar o tratamento da informação na descrição de recursos, tendo em vista o gerenciamento de dados e de informações. Segundo Alves (2010, p. 47), os metadados são:

\section{[...] atributos que representam uma entidade (objeto do mundo real) em um sistema de informação. Em outras palavras, são elementos descritivos ou atributos referenciais codificados que representam características próprias ou atribuídas às entidades; são ainda dados que descrevem outros dados em um sistema de informação, com o intuito de identificar de forma única uma entidade (recurso informacional) para posterior recuperação.}

De modo geral, pode-se dizer que o objetivo e a função dos metadados são os mesmos da disciplina de catalogação na atividade de descrever recursos no domínio bibliográfico: representar as características de forma e de conteúdo de um recurso informacional de modo padronizado, facilitando a identificação do recurso, o acesso aos dados descritivos, a localização e a recuperação de recursos. (Hsieh-Yee, 2006).

Os metadados se restringem a definição de atributos do recurso informacional e a catalogação, por sua vez, possui um escopo de atuação ampliado por sua função gestora na construção e na modelagem dos catálogos e de bancos de dados no processo de representação de recursos e de apresentação da informação em ambientes informacionais e na definição dos relacionamentos entre entidades e atributos descritivos dos recursos disponíveis em um ou mais acervos.

Nesse sentido, um sistema de informação deve priorizar a estrutura interna do domínio de conhecimento onde está inserido, pois cada domínio tem suas especificidades informacionais e diante delas escolhe-se o padrão de metadados que melhor atenda à necessidades de área de conhecimento. Todavia, em um mesmo domínio há a possibilidade da utilização de distintos padrões de metadados em diferentes instituições. Sendo Fusco (2010, p.22),

A sugestão é que, para o estudo e implementação de metadados, dado a regionalização das taxonomias que ocorre na prática, uma análise do domínio seria mais adequada, com observância das dimensões históricas e epistemológicas. Princípios gerais (não absolutos) nasceriam do confronto entre saberes de diversos domínios, o que pressupõe um redirecionamento da forma como a Ciência da Informação estuda as tecnologias de metadados de interesse comum com a Ciência da Computação.

Durante a construção do registro, são notadas muitas dificuldades na descrição das imagens digitais, pois as orientações para a descrição das propriedades do recurso imagético podem estar distribuídas em vários esquemas de descrição, como por exemplo os códigos tradicionais: Anglo-American Cataloguing Rules (AACR2r), Graphic Materials: Rules for Describing Original Items and Historical Collections e o Resource Description and Access (RDA).

O registro descritivo do recurso imagético, em muitos casos, não apresenta uma garantia de integridade, clareza, precisão, lógica e consistência das informações no registro a respeito do recurso tratado, pois as características de um recurso imagético não são abordadas e muitas vezes os atributos são valorados por características textuais apenas contextualizadas no ambiente digital.

Com isso, destacam-se que a necessidade e a importância do tratamento descritivo para a construção de formas mais eficientes para a representação e apresentação de recursos informacionais como um modo de torná-los disponíveis, acessíveis e recuperáveis, vai além da definição do padrão de metadados utilizado. 
As orientações para a descrição do material imagético digital precisam considerar as especificidades desse tipo de recurso, que em muitos casos são o que mais consiste a dificuldade do registro e de modo que a sintaxe da imagem digital seja explicitada pelos esquemas de descrição como requisito para sua representação.

O desenvolvimento de um trabalho de interpretação de metadados, na caracterização das necessidades informacionais para o acesso aos dados de um recurso em uma estrutura de persistência de dados que garanta sua integridade e qualidade, tendo como meta a descrição do recurso em um padrão específico para a imagem digital, ocorreu a partir da percepção das peculiaridades do recurso imagético digital e da necessidade da representação com qualidade dos seus elementos de persistência. Segundo Fusco (2010, p. 17),

[...] a estrutura de representação dos elementos de persistência de itens bibliográficos influencia a qualidade da informação nos processos de armazenamento, busca e recuperação dessas informações, e deve, portanto, fazer parte do processo de construção de catálogos digitais. A utilização de um padrão de metadados que tem como principal objetivo a entrada de dados e a interoperabilidade e que não considera questões de qualidade de persistência da informação pode, muitas vezes, em alguns ambientes digitais de informação que são baseados somente nesses padrões apresentarem problemas tanto nos processos de manipulação de dados quanto na recuperação das representações dos itens bibliográficos.

A garantia da persistência dos dados e o instanciamento dos itens disponíveis no banco de dados com consistência e integridade são necessários para a representação de uma imagem digital, o que requer a descrição do objeto informacional como sendo único e de modo que possa ser inserido em diferentes contextos mantendo sua integralidade. A persistência, “[...] refere-se ao armazenamento não volátil de dados. O dado é armazenado de modo que a informação não desapareça facilmente [...]” (Alves; Santos, 2013, p. 12).

Segundo Booch; Jacobson; Rumbaugh (1998, tradução nossa) a persistência de dados é uma propriedade do objeto que faz com que as informações possam existir mesmo depois que o programa que originou registro descritivo, ou o localizou, não seja o mesmo. E o instanciamento dos recursos pode ser entendido como o processo pelo qual a informação persistida atua no acesso aos dados e na recuperação do recurso representado e disponível para uso e reuso em ambientes informacionais digitais.

Da mesma forma, a persistência de dados infere no desenvolvimento monolítico do objeto, ou seja, a lógica da descrição deve demostrar sua desconstrução para a elaboração da descrição, que obedecendo a padrões determinados permite que cada elemento seja um ponto de acesso tanto ao objeto isoladamente, quanto aos relacionamentos entre outros objetos, nomes entidades, locais e outra série de elementos ontológicos e contextuais que ampliam, de forma significativa, o potencial do conhecimento sobre determinado assunto. (Lourenço, 2007).

Na perspectiva de assegurar a consistência na descrição dos dados imagéticos para sua persistência no banco de dados, considerando que isso se dá pela especificidade e detalhamento, foi realizada uma comparação por equivalência dos elementos descritivos de alguns dos esquemas utilizados na descrição da imagem digital: AACR2r (AngloAmerican Cataloguing Rules, 2nd ed. review), ISBD (International Standard Bibliographic Description); Graphic Materials: Rules for Describing Original iItems and Historical Collections; RDA (Resource Description and Access); CDWA (Categories for the Description of Works of Art) e o CCO (Cataloging Cultural Objects). E os padrões de metadados: Dublin Core; MARC 21 (Catalogação Legível por Computador); MODS (Metadata Object Description Schema); MIX (Metadata for Digital Still Images Standards Committee); IPTC Core \& Extension - Photo Metadata standard e o VRA Core Schema. E por fim a estrutura de dados automática: EXIF (Exchangeable Image File Format).

A análise desses instrumentos resultou no mapeamento dos elementos descritivos agrupados em áreas estabelecidas por uma lógica de descrição para imagem digital e pelas orientações do modelo conceitual FRBR.

A partir do estudo dos instrumentos para a descrição da imagem, nota-se que a modelagem dos dados permite uma maior economia processual, com a reutilização de componentes, o aumento da flexibilidade e a automatização do sistema, do ponto de vista informacional e tecnológico.

As regras e as práticas de modelagem elaboradas por um catalogador atuando como projetista do catálogo e podem diminuir algumas anomalias, como a repetição de campos de descrição, e ampliar a qualidade da informação homologada no modelo, permitindo que um projeto de software bem estruturado, considere, primeiramente, a camada interna - a camada de persistência de dados - onde os elementos descritivos são previamente planejados e definidos. 
Esse com a definição de dados na modelagem do sistema preveniria e auxiliaria na identificação de solução para problemas futuros ou mesmo novas funcionalidades do sistema funcional.

Dessa forma, o planejamento de como será elaborado o registro descritivo de imagens antecede a construção dos catálogos ou banco de dados, pois ele será previsto na etapa de modelagem. A definição e os relacionamento dos metadados serão estabelecidos na modelagem da camada de persistência.

Portanto, as questões-chave na representação da imagem digital são a concepção, a implementação, a definição de metadados e a representação dos valores de cada atributo, muitos deles com o preenchimento no momento de extração de imagens e elaborado dinamicamente de acordo com impressão do usuário e a captura de conteúdo, uma vez que o conteúdo imagético é correlato a várias interpretações.

Na descrição de recursos, a catalogação oferece diferentes opções de pontos de acesso para o usuário encontrar o material desejado, garantindo sua unicidade e apresentando de forma sucinta e estruturada seus atributos. Essas são características que garantem a qualidade necessária para um registro descritivo em cada domínio do conhecimento. Os elementos de descrição são determinados por esquemas de orientação para a representação, como códigos, formatos de intercâmbio de dados, padrões de metadados e modelos conceituais.

Os diferentes tipos de instrumentos de trabalho para a construção de formas de representação orientam a construção de registros descritivos na apresentação das características dos recursos tendo como fio condutor uma lógica de descrição que independentemente do seu contexto (científico, acadêmico, cultural, econômico, social, etc.) trará orientações para a construção padronizada na apresentação dos dados buscando minimizar, de alguma forma, as barreiras lingüísticas e facilitar a compreensão e a interpretação do conteúdo do registro descritivo para usuários humanos e não humanos.

Esses instrumentos contem orientações que definem a sintática e a semântica do registro descritivo de uma ou mais categorias de recursos, com o propósito de padronizar a representação otimizando os resultados no acesso aos dados, na localização da informação e na recuperação de recursos. Na tarefa de representar a informação imagética são encontrados diversos instrumentos de trabalho, entre eles se destacam os específicos para a representação do recurso visual: Graphic Materials: Rules for Describing Original Items and Historical Collections, CDWA (Categories for the Description of Works of Art), CCO (Cataloging Cultural Objects), MIX (Metadata for Digital Still Images Standards Committee), IPTC Core \& Extension for-photo metadata standard, VRA Core Schema e o EXIF (Exchangeable Image File Format).

Os padrões de metadados, entretanto, são elementos descritores que segue um determinado modelo de dados que contem um conjunto de conceitos e de requisitos, com o objetivo de descrever recursos de um domínio específico. (Barreto, 1999). Segundo El-Sherbini (2000, p. 188), os padrões de metadados “[...] têm um importante papel no suporte ao uso de serviços e recursos eletrônicos. No entanto, para maximizar o uso destes e assegurar consistência, são necessários padrões universalmente aceitos que orientem a criação de metadados".

No mapeamento dos atributos definidos nos instrumentos do tratamento descritivo da informação utilizados para a descrição de recursos imagéticos considerou-se o maior detalhamento da descrição para esse tipo de material e os elementos com maior incidência nos padrões o que resultou nas informações contidas nos Quadros I e II.

O Quadro I apresenta os elementos descritivos presentes, com maior incidência, nos instrumentos analisados:

\begin{tabular}{|l|l|}
\hline CATEGORIZAÇÃO & ELEMENTOS DESCRITIVOS \\
\hline \multirow{2}{*}{ OBJETO IMAGEM } & Nível da catalogação* \\
& Tipo do objeto/obra* \\
& Partes e componentes \\
& Observações \\
\hline \multirow{2}{*}{ TÍTULO } & Título * \\
& Tipo equivalente* \\
& Idioma \\
& Data relacionada ao título \\
\hline \multirow{2}{*}{ DERIVAÇÃO } & Descrição da derivação \\
& Extensão do criador \\
& Qualificação do criador \\
\hline
\end{tabular}




\begin{tabular}{|c|c|}
\hline & $\begin{array}{l}\text { Título do criador* } \\
\text { Data de criação * } \\
\text { Localização da criação* } \\
\text { Observações }\end{array}$ \\
\hline ESTILOS / PERÍODOS / GRUPOS / MOVIMENTOS & $\begin{array}{l}\text { Estilo do período } \\
\text { Tipo do período }\end{array}$ \\
\hline DIMENSÕES & $\begin{array}{l}\text { Descrição dimensões * } \\
\text { Tipo de dimensões } \\
\text { Valor das dimensões* } \\
\text { Unidade das dimensões } \\
\text { Extensão* } \\
\text { Forma* } \\
\text { Formato / Tamanho* }\end{array}$ \\
\hline MATERIAIS E TÉCNICAS & $\begin{array}{l}\text { Materiais / Técnicas de Descrição* } \\
\text { Materiais / Técnicas de Extensão* } \\
\text { Coloração* } \\
\text { Marcas d'água* } \\
\text { Ações desempenho } \\
\text { Observações }\end{array}$ \\
\hline EDIÇÃO & $\begin{array}{l}\text { Descrição da edição* } \\
\text { Número da edição }\end{array}$ \\
\hline ORIENTAÇÃO & Orientação* \\
\hline DESCRIÇÃO FÍSICA & $\begin{array}{l}\text { Tipo de Arquivo* } \\
\text { Codificação } \\
\text { Tamanho* } \\
\text { Velocidade de transmissão } \\
\text { Tipo de dados } \\
\text { Tipo de objeto }\end{array}$ \\
\hline CONDIÇÃO DA IMAGEM & $\begin{array}{l}\text { Abertura da lente } \\
\text { Coloração* } \\
\text { Compensação de exposição } \\
\text { Contraste* } \\
\text { Distância focal } \\
\text { Flash } \\
\text { ISO* } \\
\text { Nitidez* } \\
\text { Saturação* }\end{array}$ \\
\hline CONTEXTO & $\begin{array}{l}\text { Identificação de evento históricos / cultural* } \\
\text { Data do Evento* } \\
\text { Local do Evento* } \\
\text { Contexto arquitetônico } \\
\text { Contexto arqueológico } \\
\text { Localização histórica }\end{array}$ \\
\hline NOTAS DESCRITIVAS & Nota descritiva* \\
\hline TRABALHOS RELACIONADOS & $\begin{array}{l}\text { Tipo de relação de trabalho* } \\
\text { Data de relação de trabalho* } \\
\text { Contexto mais amplo de trabalho } \\
\text { Observações }\end{array}$ \\
\hline LOCALIZAÇÃO & $\begin{array}{l}\text { Localização* } \\
\text { Número de identificação* } \\
\text { Galeria } \\
\text { Observações }\end{array}$ \\
\hline DIREITOS AUTORAIS & $\begin{array}{l}\text { Declaração de direitos autorais* } \\
\text { Observações }\end{array}$ \\
\hline
\end{tabular}

Quadro I. Elementos bibliográficos descritivos necessários para a o registro da imagem digital. Fonte: Simionato, 2012 , p. 91. 
Os elementos mapeados e destacados por um asterisco $(*)$, nos quadros I e II, representam atributos essenciais para a descrição da imagem digital por carregarem informações que garantem a consistência dos dados e sua persistência na base.

O Quadro II aponta os elementos para o controle de autoridade e de assunto com maior incidência nos instrumentos analisados:

\begin{tabular}{|c|c|c|c|}
\hline $\begin{array}{ll}\text { TIPO } & \text { DE } \\
\text { AUTORIDADE } & \end{array}$ & $\begin{array}{l}\text { AUTORIDADE PARA } \\
\text { PESSOA / } \\
\text { ENTIDADE } \\
\text { COLETIVA }\end{array}$ & $\begin{array}{l}\text { AUTORIDADE PARA } \\
\text { LUGAR }\end{array}$ & $\begin{array}{l}\text { AUTORIDADE PARA } \\
\text { ASSUNTO }\end{array}$ \\
\hline $\begin{array}{l}\text { ELEMENTO } \\
\text { DESCRITIVO }\end{array}$ & $\begin{array}{l}\text { Tipo de registro } \\
\text { Autoridade } \\
\text { Pessoa / Nome Pessoa } \\
\text { Coletiva* } \\
\text { Responsabilidade* } \\
\text { Linguagem* } \\
\text { Data nome } \\
\text { Biografia } \\
\text { Data de nascimento } \\
\text { Data da morte } \\
\text { Local de Nascimento } \\
\text { Nacionalidade } \\
\text { Evento* } \\
\text { Data* } \\
\text { Lugar* } \\
\text { Pessoa Vinculada } \\
\text { Pessoa Coletiva* }\end{array}$ & $\begin{array}{l}\text { Autoridade lugar - Tipo } \\
\text { de registro* } \\
\text { Local* } \\
\text { Idioma* } \\
\text { Coordenadas Geográficas } \\
\text { Tipos lugar } \\
\text { Locais relacionados }\end{array}$ & $\begin{array}{l}\text { Tipo de registro assunto } \\
\text { Autoridade* } \\
\text { Termo de classificação* } \\
\text { Nome da Entidade* } \\
\text { Data assunto } \\
\text { Funções sujeito } \\
\text { Atributos } \\
\text { Assunto relacionado* } \\
\text { Tipo de Relação assunto } \\
\text { Contexto mais amplo } \\
\text { assunto* } \\
\text { Relação lugar } \\
\text { Pessoa Vinculada } \\
\text { Pessoa Coletiva* } \\
\text { Tipo de Relação pessoa* } \\
\text { Nota descritiva assunto } \\
\text { Fonte nota } \\
\text { Observações }\end{array}$ \\
\hline
\end{tabular}

Quadro II. Elementos para o controle autoridade e assunto. Fonte: Adaptado de Simionato, 2012, p. 92.

O mapeamento dos elementos de descrição demonstra que o tratamento da imagem digital tem suas especificidades e ela se configura como um recurso informacional singular que exige uma estrutura lógica em sua descrição que permita a cada elemento seja atribuído como valor exato e considere sua identidade como recurso informacional.

Esse mapeamento ressalta que a representação da imagem digital necessita de uma estrutura que garanta a descrição dos atributos de modo flexível e a integralidade do objeto representado, favorecendo o acesso ao objeto isoladamente e também aos seus relacionamentos com outros objetos, nomes entidades, locais e outra série de elementos ontológicos e contextuais ampliando o potencial de acesso e recuperação de dados e de informação para a apropriação do conhecimento sobre determinado assunto.

A descrição de imagens digitais a necessita de consistência em sua representação para o atendimento das necessidades do domínio do conhecimento em que a imagem está inserida.

A adoção da metodologia de modelagem conceitual de dados permite ao catalogador atuar no processo de construção de banco de dados que reflitam os conceitos da catalogação, possibilitando uma visão não linear dos elementos descritivos de um item imagético. É importante esclarecer que a modelagem se faz pelos dados dos registros descritivos, ou seja, pelos elementos descritivos.

Uma das soluções para o controle dos dados não apresentarem anomalias é a utilização do modelo conceitual FRBR (Functional Requirements for Bibliographic Records) para o desenvolvimento de projetos e a garantia de especificidade dos tipos de recursos informacionais na construção de registros descritivos em diferentes domínios.

\section{MODELAGEM CONCEITUAL PARA A DADOS IMAGÉTICOS DIGITAIS.}

Nos sistemas de informação a modelagem conceitual de dados na construção de catálogos e bancos de dados consolida os processos referentes ao cenário que o sistema se propõe a atender. 
Nesse sentido, a utilização de uma arquitetura para o ambiente informacional digital com base no modelo conceitual de requisitos bibliográficos pode auxiliar no processo de representação de imagens digitais.

O modelo conceitual utilizado neste estudo foi o FRBRer (Functional Requirements for Bibliographic Records entity-relationship), que segundo o idealizador Peter Chen (1990) o modelo de dados de um sistema deve conter um alto nível de abstração que por meio de uma visão estática de um programa e pela definição de uma organização dos dados, maximaliza a utilidade e apresenta as características essenciais de um domínio de abstração.

O modelo FRBRer estabelece alguns conceitos sobre os muitos tipos de materiais descritos nas bases de dados pertencentes a instituições do patrimônio cultural, como bibliotecas, arquivos e museus entre outras, na tentativa de tornar os catálogos automatizados mais amigáveis para os usuários, e universais, tendo como propósito favorecer compatibilidades internacionais, de modo a tornar o acesso aos dados e os processos de busca e de recuperação cada vez mais eficientes. Segundo Le Bouef (2007, p. 1), o FRBR

[...] é um modelo que define um número de classes gerais ("entidades") de coisas que são julgadas relevantes no contexto específico de um catálogo de biblioteca, seguidas de características ("atributos") que pertencem a cada uma dessas classes gerais, e os relacionamentos que podem existir entre instâncias dessas várias classes.

A modelagem conceitual E-R para imagens digitais, incorporando os conceitos da Ciência da Informação e Ciência da Computação pode auxiliar no desenvolvimento e no planejamento de catálogos de recursos imagéticos digitais na configuração e na apresentação das informações para o atendimento das tarefas do usuário.

Na construção de um catálogo, o FRBR dá continuidade ao objetivo da elaboração de catálogos, tendo como diferencial o aprimoramento no processo de oferecer uma nova perspectiva sobre a estrutura e as relações dos registros bibliográficos. Pois, os usuários desejam sanar suas necessidades e encontrar o recurso da forma mais conveniente, sendo que o usuário não deverá “[...] manusear todas as outras formas de registro disponíveis no acervo, mesmo que os itens estivessem ampla e corretamente organizados, nós, bibliotecários, elaboramos representações desses itens, de forma a simplificar a busca.” (Mey, 1995, p. 1).

A partir de orientações do FRBRer e das performances de desempenho dos relacionamentos para a descrição das imagens digitais e dos conceitos de construção da modelagem conceitual, Simionato (2012) desenvolve o modelo conceitual para recursos imagéticos denominado: Requisitos Funcionais para Dados Imagéticos Digitais - RFDID.

O Grupo 1 representa a base conceitual do modelo, referindo-se ao trabalho intelectual ou artístico, suas entidades são: obra, expressão, manifestação e item. Como apresentado o Grupo 1, no Quadro III.

\begin{tabular}{|l|l|}
\hline Entidade & Descrição \\
\hline Obra & Definida como a criação intelectual subjetiva de quem irá capturar uma imagem. \\
\hline Expressão & $\begin{array}{l}\text { Realização intelectual ou artística específica e ainda subjetiva, que assume uma } \\
\text { obra ao ser elaborada, ou seja, a expressão no contexto imagético é o processo de } \\
\text { criação intelectual a ser transformada em imagem digital, ou seja, a transformação em } \\
\text { pixels. }\end{array}$ \\
\hline Manifestação & Forma física e concreta da expressão de uma obra. \\
\hline Item & $\begin{array}{l}\text { Imagem que o usuário busca em um catálogo, é a imagem que se vê e a sua } \\
\text { representação deve conter atributos que a tornem única a partir de uma descrição de } \\
\text { dados persistidos no sistema que garantam o seu instanciamento. }\end{array}$ \\
\hline
\end{tabular}

Quadro III. Entidades do Grupo 1 do RFDID. Fonte: Autoras.

Com base nas quatro entidades do grupo 1, os relacionamentos entre as entidades e entre eles, é apresentado o primeiro grupo de entidades do RFDID na Figura 1. 


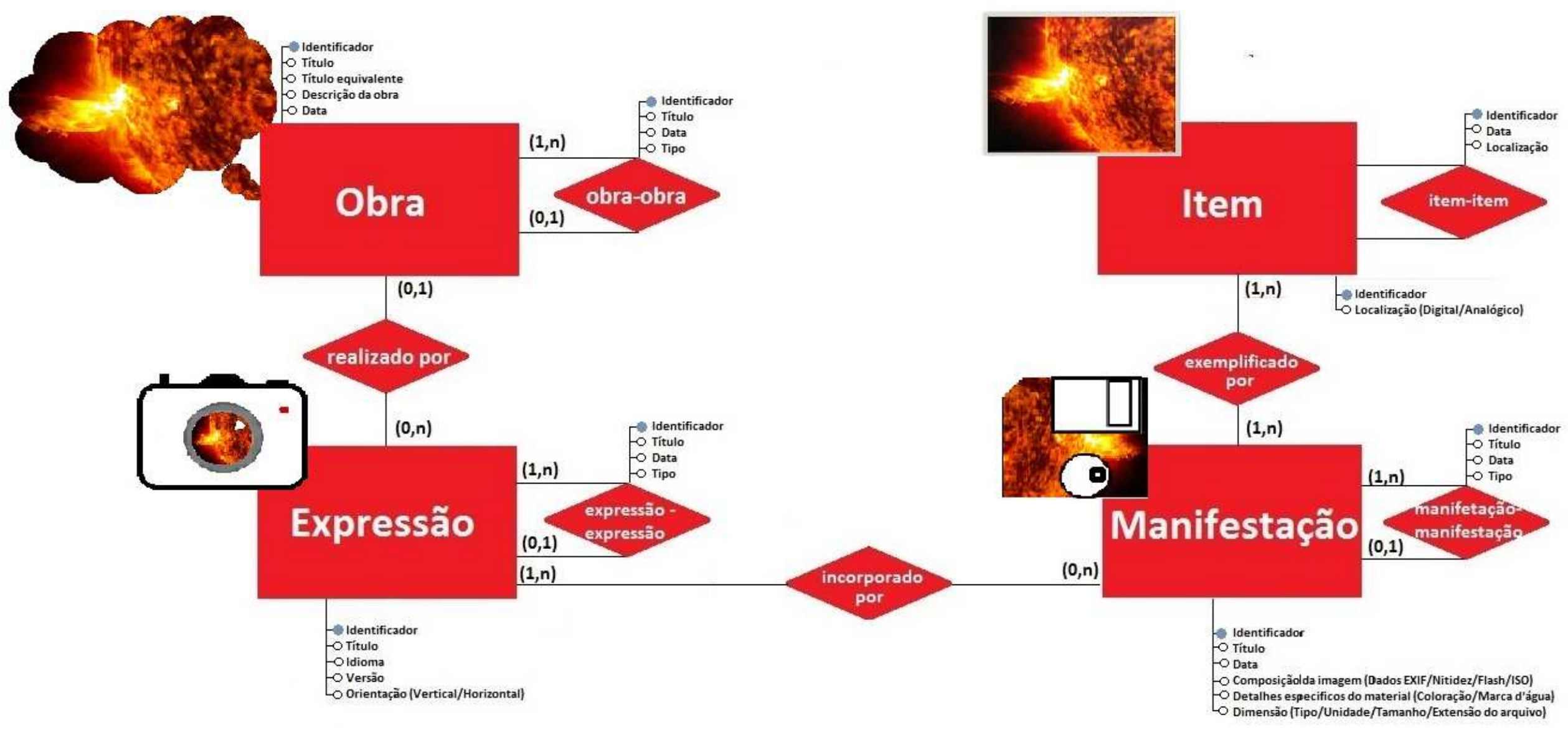

Figura 1. RFDID - Primeiro grupo de entidades e seus relacionamentos. 
O modelo conceitual - RFDID será contextualizado a partir da Figura 2 e sua descrição, uma imagem selecionada do projeto The Commons do Flickr, que requisita apenas o direito de atribuição e contém informações necessárias para a descrição do recurso.

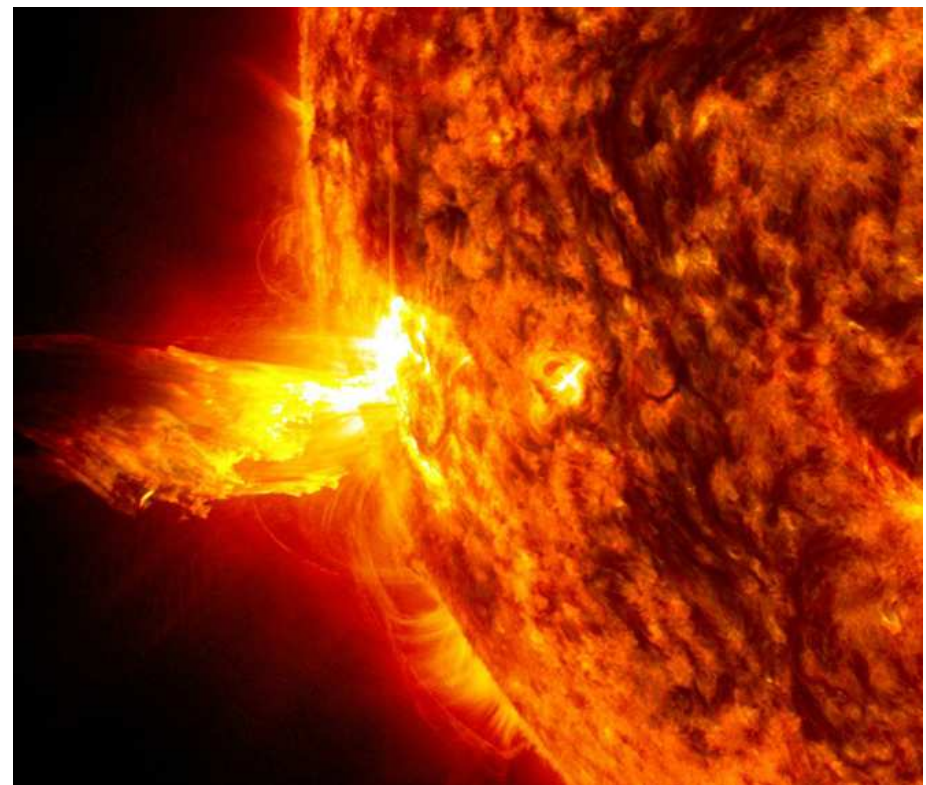

Figura 2. Sun Emits a Solstice CME. Fonte: NASA Goddard Space Flight Center. 2013. Disponível em: $<$ http://www.flickr.com/photos/gsfc/9103297092/in/photostream/>. [Acesso em: 8 de julho de 2013].

O recurso apresentado na Figura 2 apresenta em sua página de acesso a seguinte descrição:

Caption: This image from June 20, 2013, at 11:15 p.m. EDT shows the bright light of a solar flare on the left side of the sun and an eruption of solar material shooting through the sun's atmosphere, called a prominence eruption. Shortly thereafter, this same region of the sun sent a coronal mass ejection out into space.

On June 20, 2013, at 11:24 p.m., the sun erupted with an Earth-directed coronal mass ejection or CME, a solar phenomenon that can send billions of tons of particles into space that can reach Earth one to three days later. These particles cannot travel through the atmosphere to harm humans on Earth, but they can affect electronic systems in satellites and on the ground.

Experimental NASA research models, based on observations from NASA's Solar Terrestrial Relations Observatory and ESA/NASA's Solar and Heliospheric Observatory show that the CME left the sun at speeds of around 1350 miles per second, which is a fast speed for CMEs.

Earth-directed CMEs can cause a space weather phenomenon called a geomagnetic storm, which occurs when they funnel energy into Earth's magnetic envelope, the magnetosphere, for an extended period of time. The CME's magnetic fields peel back the outermost layers of Earth's fields changing their very shape. Magnetic storms can degrade communication signals and cause unexpected electrical surges in power grids. They also can cause aurora. Storms are rare during solar minimum, but as the sun's activity ramps up every 11 years toward solar maximum - currently expected in late 2013 -- large storms occur several times per year.

In the past, geomagnetic storms caused by CMEs of this strength and direction have usually been mild.

Credit: NASA/Goddard/SDO

NASA image use policy.

NASA Goddard Space Flight Center enables NASA's mission through four scientific endeavors: Earth Science, Heliophysics, Solar System Exploration, and Astrophysics. Goddard plays a leading role in NASA's accomplishments by contributing compelling scientific knowledge to advance the Agency's mission.

Informações adicionais: Alguns direitos reservados (direito de atribuição) - Creative Commons.
Fonte:
NASA
Goddard
Space
Flight
Center,
2013.
Disponível
em: $<$ http://www.flickr.com/photos/gsfc/9103297092/in/photostream/>. [Acesso em: 8 de julho de 2013].

Os valores correspondentes aos atributos de cada entidade estão ligados ao seu conteúdo e relacionamento específico e serão elaborados a partir das informações disponíveis na página onde a imagem "Sun Emits a Solstice 
$C M E$ " está armazenada no repositório do Flickr. Alguns dos atributos são título, idioma, descrição da imagem, imagens relacionadas, tipo, dados EXIF (disponíveis em $<$ http://www.flickr.com/photos/gsfc/9103297092/meta/in/photostream>) e localização do item, o número de URI (Identificador Uniforme de Recursos) <photos/gsfc/9103297092>.

No segundo grupo, as entidades são Pessoa e Entidade Coletiva explicitadas no Quadro IV, elas estruturam a base das entidades do primeiro grupo: pessoa e entidade coletiva:

\begin{tabular}{|c|l|}
\hline Entidade & \multicolumn{1}{c|}{ Descrição } \\
\hline Pessoa & $\begin{array}{l}\text { Indivíduo responsável pela criação ou realização de uma obra, ou seja, o responsável } \\
\text { pela captura da imagem digital ou por sua realização. }\end{array}$ \\
\hline Entidade coletiva & $\begin{array}{l}\text { Organizações ou grupos de indivíduos responsáveis pelo conteúdo intelectual da } \\
\text { imagem digital, inclusive grupos temporários (encontros, conferências, reuniões, } \\
\text { festivais, etc.) e autoridades territoriais como uma federação, um estado, uma região, } \\
\text { entre outros. }\end{array}$ \\
\hline
\end{tabular}

Quadro IV. Entidades do Grupo 2 do RFDID. Fonte: Autoras.

As entidades do Grupo 2 do RFDID e seus relacionamentos, estão presentes na ilustração do segundo grupo de entidades do RFDID na Figura 3. Os valores exatos dos atributos deste exemplo são autor/responsável pelo recurso imagético "Sun Emits a Solstice CME" armazenado no repositório do Flickr.

O terceiro grupo, por sua vez, corresponde às entidades que representam o conjunto de temas caracterizadores de uma obra, conforme demonstra o Quadro V.

\begin{tabular}{|c|l|}
\hline Entidade & \multicolumn{1}{c|}{ Descrição } \\
\hline Conceito & $\begin{array}{l}\text { Uma noção abstrata ou uma ideia que podem ser amplas ou específicas, abrangendo } \\
\text { abstrações de uma obra e podem ser temáticas: áreas de conhecimento, disciplinas, } \\
\text { escolas de pensamento, teorias; ou ainda as técnicas fotográficas que podem ser } \\
\text { incorporadas nas imagens digitais. }\end{array}$ \\
\hline Objeto & $\begin{array}{l}\text { A coisa material, que abrange uma completa categoria de coisas materiais que podem } \\
\text { ser as temáticas de uma obra: objetos da natureza, objetos da criação humana ou } \\
\text { objetos que já não existam. }\end{array}$ \\
\hline Evento & $\begin{array}{l}\text { Inclui uma variedade de ações, ocorrências ou acontecimentos: momento histórico, } \\
\text { época, período de tempo }\end{array}$ \\
\hline Lugar & $\begin{array}{l}\text { Uma localização ou uma série de localizações como: terrestres e extraterrestres, } \\
\text { históricas ou contemporâneas, características geográficas e jurisdições geopolíticas. }\end{array}$ \\
\hline \multicolumn{2}{|l}{ Quadro V. Apresentação de Entidades do Grupo 3 do RFDID. Fonte: Autoras. }
\end{tabular}

As informações que comporão aos valores exatos de cada atributo correspondente a imagem, podem ser encontradas na descrição da imagem "Sun Emits a Solstice CME” e também em descrições disponíveis em enciclopédias, dicionários e/ou outras fontes.

As entidades do segundo e terceiro grupo estão descritas na Figura 3, demonstrando a potencialidade representativa do modelo FRDID: 


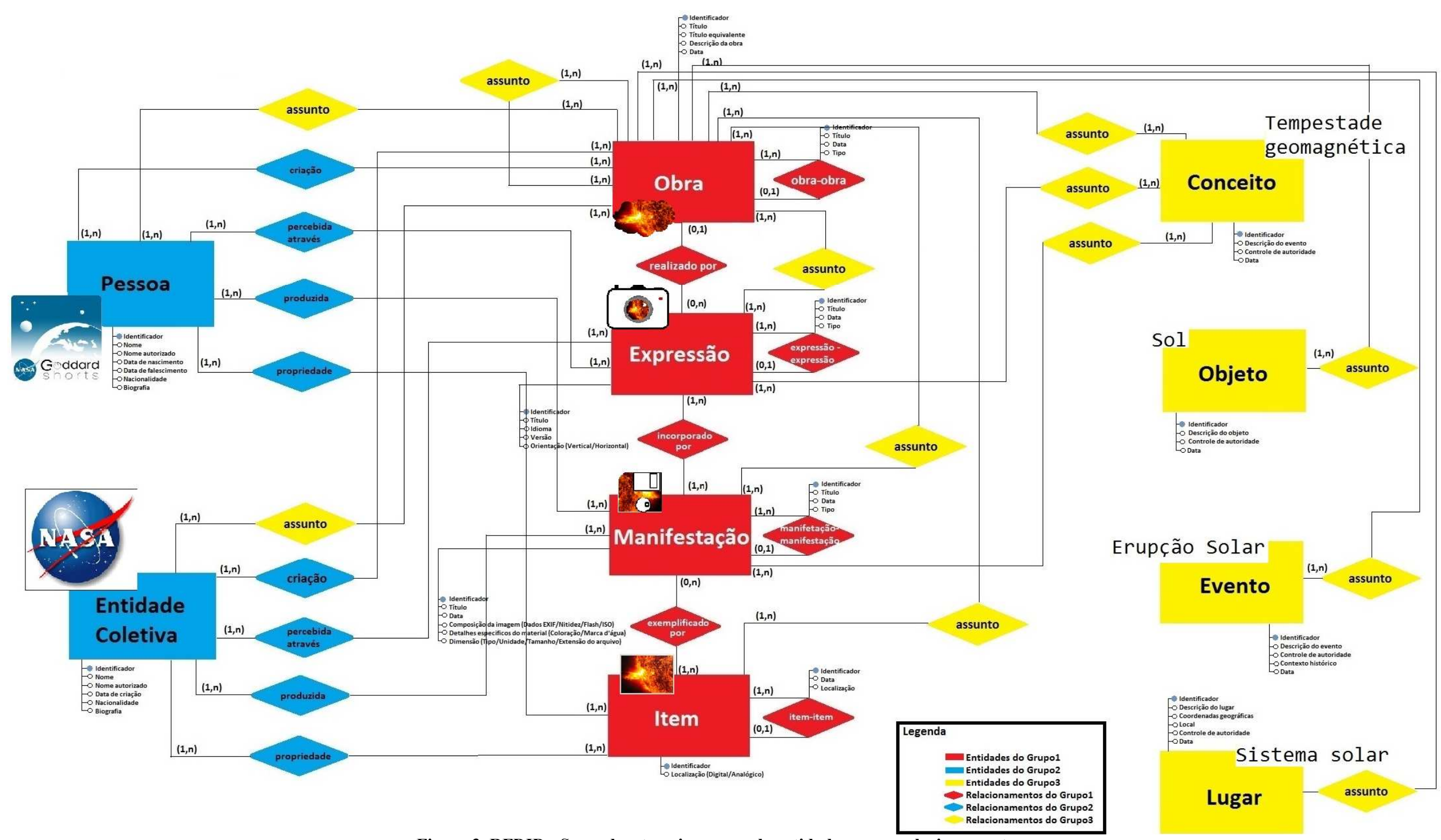

Figura 3. RFDID - Segundo e terceiro grupo de entidades e seus relacionamentos. 
Uma descrição construída tendo como base o modelo RFDID poderá abranger instâncias dentre as várias entidades presentes no modelo conceitual. No entanto, o modelo conceitual não descreve o recurso imagético é responsável somente, pela modelagem de seus dados, a descrição dos recursos informacionais é orientada pelos códigos de catalogação e diretrizes de descrição.

O RFDID é um modelo que define um número de entidades relevantes para a descrição de recursos imagéticos em contextos específicos, com atributos de cada uma dessas entidades e os relacionamentos que podem existir entre instâncias dessas várias entidades.

A imagem "Sun Emits a Solstice CME" foi descrita a partir do padrão de metadados IPTC Core \& Extension forphoto metadata standard, escolhido pela sua proveniência imagética, capaz de abrigar algumas especificidades do material, como pode ser observada na descrição no Quadro VI.

\begin{tabular}{|c|c|}
\hline IPTC CORE FIELDS & DESCRIPTION \\
\hline \multicolumn{2}{|l|}{ Creator's contact details } \\
\hline Creator & NASA's Marshall Space Flight Center \\
\hline Creator's Job Title & Sun Emits a Solstice CME (NASA, International Space Station, 21/06/13) \\
\hline $\begin{array}{l}\quad \text { Creator's Contact } \\
\text { (Address, } \\
\text { State/Province, Postal } \\
\text { City, } \\
\text { Country, Phone, } \\
\text { Website) }\end{array}$ & $\begin{array}{l}\text { NASA Headquarters } \\
\text { Public Affairs, Photo Department } \\
300 \text { E Street, SW } \\
\text { Washington, DC } 20546\end{array}$ \\
\hline \multicolumn{2}{|l|}{ Formal Image description } \\
\hline Date Created & 20 de junho de 2013 \\
\hline 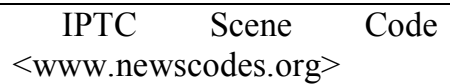 & Colorspace \\
\hline $\begin{array}{l}\text { Location } \begin{array}{r}\text { (Sublocation, } \\
\text { City, }\end{array} \text { State/Provoince, } \\
\text { Country, ISO Country Code) }\end{array}$ & Space \\
\hline \multicolumn{2}{|l|}{ Visual content description } \\
\hline Headline & Sun Emits a Solstice CME \\
\hline Description & $\begin{array}{l}\text { This image from June 20,2013, at } 11: 15 \text { p.m. EDT shows the bright light of } \\
\text { a solar flare on the left side of the sun and an eruption of solar material shooting } \\
\text { through the sun's atmosphere, called a prominence eruption. Shortly thereafter, } \\
\text { this same region of the sun sent a coronal mass ejection out into space. }\end{array}$ \\
\hline Keywords & NASA; CME; Solstice \\
\hline IPTC Subject Code & (N1TS/G2KI) \\
\hline Description Writer & $\begin{array}{l}\text { The subject of the photographs are making these official NASA photographs } \\
\text { available for publication by news organizations and/or for personal use printing. } \\
\text { NASA may not use the photographs in materials, advertisements, products, or } \\
\text { promotions that in any way suggest approval or endorsement. }\end{array}$ \\
\hline \multicolumn{2}{|c|}{ Workflow and Copyright Information } \\
\hline Title & Sun Emits a Solstice CME \\
\hline Job ID & - \\
\hline Instructions & All Images used must credited. \\
\hline Credit Line & Creative Commons \\
\hline Source & http://www.flickr.com/photos/gsfc/9103297092/in/photostream \\
\hline Copyright Notice & - \\
\hline Rights Usage Terms & Some rights. \\
\hline
\end{tabular}

Quadro VI. Descrição de "Sun Emits a Solstice CME” com o IPTC Core \& Extension. Fonte: Autoras. 
Os relacionamentos entre os dados do IPTC Core \& Extension e o modelo conceitual RFDID estão representados no quadro VII, com base na descrição imagética de "Sun Emits a Solstice CME".

\begin{tabular}{|c|c|c|}
\hline ENTIDADE & $\begin{array}{l}\text { CAMPO DESCRITIVO } \\
\text { (IPTC CORE } \text { FIELDS) }\end{array}$ & RELACIONAMENTO \\
\hline \multicolumn{3}{|l|}{ GRUPO 1} \\
\hline Obra & $\begin{array}{l}\text { Creator } \\
\text { Date Created } \\
\text { Title }\end{array}$ & $\begin{array}{l}\text { Expressão, Manifestação, Item e } \\
\text { Entidades do GRUPO } 2 \text { e } 3\end{array}$ \\
\hline Expressão & $\begin{array}{l}\text { IPTC Scene Code } \\
\text { Headline } \\
\text { Description } \\
\text { Title }\end{array}$ & $\begin{array}{c}\text { Obra, Manifestação, Item e } \\
\text { Entidades do GRUPO 2 e } 3\end{array}$ \\
\hline Manifestação & $\begin{array}{l}\text { Title } \\
\text { Instructions } \\
\text { Credit Line } \\
\text { Rights Usage Terms }\end{array}$ & $\begin{array}{l}\text { Obra, Expressão, Item e Entidades } \\
\text { do GRUPO } 2 \text { e } 3\end{array}$ \\
\hline Item & Source & $\begin{array}{l}\text { Obra, Expressão, Manifestação e } \\
\text { Entidades do GRUPO } 2 \text { e } 3\end{array}$ \\
\hline \multicolumn{3}{|l|}{ GRUPO 2} \\
\hline Pessoa & $\begin{array}{l}\text { Creator } \\
\text { Creator's Contact Details }\end{array}$ & Entidades do GRUPO 1 \\
\hline Entidade coletiva & $\begin{array}{l}\text { Creator } \\
\text { Creator's Job Title } \\
\text { Creator's Contact Details } \\
\text { Description Writer } \\
\text { Instructions } \\
\end{array}$ & Entidades do GRUPO 1 \\
\hline \multicolumn{3}{|l|}{ GRUPO 3} \\
\hline Conceito & $\begin{array}{l}\text { Description } \\
\text { Description Writer } \\
\text { Keywords }\end{array}$ & Entidades do GRUPO 1 e 2 \\
\hline Objeto & $\begin{array}{l}\text { Description } \\
\text { Description Writer } \\
\text { Keywords }\end{array}$ & Entidades do GRUPO 1 e 2 \\
\hline Evento & $\begin{array}{l}\text { Description } \\
\text { Description Writer } \\
\text { Keywords }\end{array}$ & Entidades do GRUPO 1 e 2 \\
\hline Lugar & $\begin{array}{l}\text { Description } \\
\text { Description Writer } \\
\text { Keywords }\end{array}$ & Entidades do GRUPO 1 e 2 \\
\hline
\end{tabular}

Quadro VII. Relacionamentos entre os dados do IPTC Core \& Extension e RFDID. Fonte: Autoras.

No Quadro VII pode ser notada a repetição de alguns elementos descritivos, entretanto essa repetição, no momento da modelagem de dados em um catálogo, não ocorrerá, pois esses mesmos valores estarão descritos de forma relacional.

A modelagem conceitual para recursos imagéticos definido Simionato (2012) está integralmente apresentada na Figura 4, onde constam os três grupos conceituais e seus relacionamentos e atributos. 


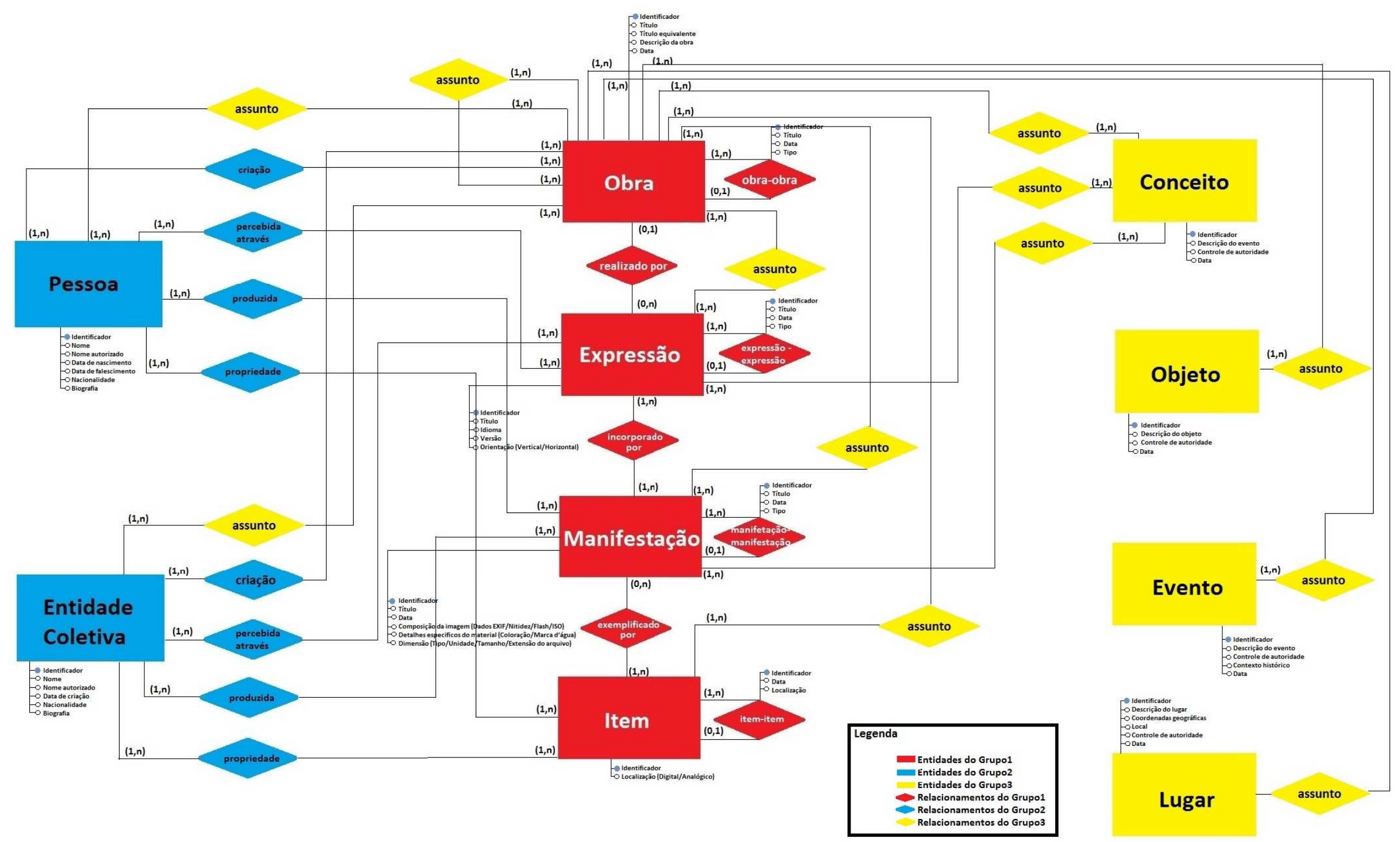

Figura 4. Requisitos Funcionais para Dados Imagéticos Digitais. 
Os Requisitos Funcionais para Dados Imagéticos Digitais - RFDID pressupõem um sistema de recuperação da imagem digital que envolve a extração de características específicas da imagem indo além do conteúdo da informação extraído da leitura da imagem e a sua descrição em texto, normalmente baseada na interpretação do assunto da imagem, ou na descrição de dados técnicos extraídos automaticamente.

A contribuição do RFDID para a área de descrição dos recursos informacionais e para área da imagem digital é o estabelecimento de um nível de organização dos dados nos sistemas digitais e um grau de padronização que pode favorecer a interoperabilidade entre sistemas e possibilitar o compartilhamento de dados e de serviços informacionais.

\section{CONSIDERAÇÕES FINAIS.}

A área de Ciência da Informação está vivenciando transformações tanto no processo do fazer quanto no modo de pensar as novas maneiras de representar e de apresentar o objeto informacional resultante do aumento do fluxo informacional.

Os recursos imagéticos, nesse contexto, são um grande atrativo no processo de comunicação e se configuram como ícones de rápida interpretação e além disso imagem possui um grande valor de representação, pois são capazes de representar coisas concretas e abstratas que não estão expressas por caracteres. Tais características também configuram o registro imagético pelo seu grau de dificuldade na representação, pela sua subjetividade de valores sintáticos e semânticos.

Para o desenvolvimento de catálogos otimizados, mais amigáveis e eficientes são necessários fatores que geram uma crescente necessidade de tratamento descritivo específico para a sua representação do recurso imagético. E a transformação desse tipo de recurso disponível em informação acessível solicita que a persistência de dados nos catálogos ou banco de dados, que descrevam de modo consistente o recurso, facilitando a sua identificação e localização, permitindo o seu instanciamento para uso, reuso e preservação da informação e a apropriação do conhecimento.

Há que se considerar, entretanto, que a representação de imagens digitais na Web é uma tarefa bastante complexa que exige cooperação, responsabilidade e especialidade para o desenvolvimento de um trabalho estratégico no uso de esquemas e de linguagens para a construção de formas de representação estruturadas para a persistência de dados e para a apresentação da informação, estruturas essas responsáveis pelo encaminhamento de operações de acesso aos dados, de busca de informações, de localização e de recuperação de recursos informacionais.

Nesse sentido, o modelo conceitual para a descrição de imagens digitais, Requisitos Funcionais para Dados Imagéticos Digitais - RFDID aqui apresentado, se configura em uma proposta de construção de formas mais eficientes para representar o recurso imagético de modo a torná-lo disponível, acessível e recuperável.

A utilização dos RFDID na modelagem de dados permitirá uma maior economia processual, com a reutilização de componentes e o aumento da flexibilidade. A reutilização de seus componentes promove aos dados um relacionamento de seus valores conectivos as entidades previamente definidas pelo modelo conceitual e permitirá que os dados imagéticos sejam descritos somente uma vez. A flexibilidade, por sua vez, contemplará as mudanças que possam ocorrer em diferentes ambientes digitais.

Desse modo, conclui-se que o modelo apresentado oferece uma quebra na estrutura dos registros descritivos, até então, estruturados como um monólito e os transforma em estruturas de dados que podem se relacionar a partir de suas entidades e atributos, otimizando tanto os processos de descrição e de acesso, quanto os de localização e de recuperação dos recursos imagéticos e ainda favorecendo a interoperabilidade entre sistemas.

\section{REFERÊNCIAS.}

ALVES, R.C.V. Metadados como elementos do processo de catalogação. Tese (Doutorado em Ciência da Informação) - Faculdade de Filosofia e Ciências, Universidade Estadual Paulista, Marília, 2010.

ALVES, R.C.V. y SANTOS, P.L.V.A.C. Metadados no domínio bibliográfico. Rio de Janeiro: Intertexto, 2013.

BARRETO, C.M. Modelo de metadados para a descrição de documentos eletrônicos na Web. 1999. 190f. Dissertação (Mestrado em Ciências em Sistemas de Computação) - Instituto Militar de Engenharia, Rio de Janeiro, 1999.

BOOCH, G.; JACOBSON, I. y RUMBAUGH, J. Object-oriented analysis and design with applications. Grady Booch: Boston, 1998. 
CHEN, P. Modelagem de dados: a abordagem entidade-relacionamento para projeto lógico. São Paulo: Mcgraw Hill, 1990.

EL-SHERBINI, M. Metadata and the future of cataloging. Library computing, 2000, vol. 19, no 3 y 4, p. 180-191.

FUSCO, E. Modelos conceituais de dados como parte do processo da catalogação: perspectiva de uso dos FRBR no desenvolvimento de catálogos bibliográficos digitais. Tese (Doutorado em Ciência da Informação) - Faculdade de Filosofia e Ciências, Universidade Estadual Paulista, Marília, 2010.

HAYAMA, T.; KIYOKI, Y. y KITAGAWA, T. A metadatabase system for semantic image search by a mathematical model of meaning. ACM SIGMOD Record, 1994, vol. 23, no 4, p. 34-41.

HSIEH-YEE, I. Organizing audiovisual and electronic resources for access: a cataloging guide. Washington: Library of Congress, 2006.

LE BOEUF, P. O Admirável mundo novo do FRBR. En: Reunião da IFLA de especialistas para um código de catalogação internacional (IME ICC 5), 14-15 de agosto, 2007, Pretória, África do Sul. Anais. Tradução de Fernanda Moreno; Revisão de Márcia Rosetto. em:<http://www.imeicc5.com/download/portuguese/Presentations2c_BraveNewFRBRWorld(PR)_Port.pdf $>$. [Acesso em: 10 de junio de 2013].

LOURENÇO, C.A. Análise do padrão brasileiro de metadados de teses e dissertações segundo o modelo entidaderelacionamento. Tese (Doutorado em Ciência da Informação) - Universidade Federal de Minas Gerais, Belo Horizonte, 2005.

MEY, E.S.A. Introdução à catalogação. Brasília: Briquet de Lemos, 1995.

NASA Goddard Space Flight Center. Sun Emits a Solstice CME [online]. 2013. Disponível em: $<$ http://www.flickr.com/photos/gsfc/9103297092/in/photostream/>. [Acesso em: 8 de julho de 2013].

SANTOS, P.L.V.A.C. Catalogação revisitada: sua história e contemporaneidade. Tese (Livre-docência) - Faculdade de Filosofia e Ciências, Universidade Estadual Paulista, Marília, 2010.

SIMIONATO, A.C. Representação, acesso, uso e reuso da imagem digital. Dissertação (Mestrado em Ciência da Informação) - Universidade Estadual Paulista "Júlio de Mesquita Filho", Faculdade de Filosofia e Ciências, Marília/SP, 2012. 